\title{
Assessment of Asthmas' Quality Life Style among Children Aged 1-12 Years in Al Noor Pediatric Hospital in Hilla City
}

\author{
Saadya Hadi Humade ${ }^{1}$, Aleemmerdass Kudhair ${ }^{2}$ \\ ${ }^{1}$ Professor, PhD, Maternal Neonatal Health Nursing/Al-mustaqbal University College, Xray Department, \\ ${ }^{2}$ Lecture, M.Sc, Health Community/Nursing Department, Al-Furat AL-Awsat Technical University, \\ Babel Technical Institute, Iraq
}

\begin{abstract}
Objective: To assess the quality of lifestyle among asthmatic children.

Population and Method: A descriptive study carried out inAl Noor pediatric hospital in Hilla City, during the period 1/5/2020-30/5/2020, the population was (100) children aged 1-12 years; data were collected by questionnaire through direct interview with the mother or caregiver and the child.

Data analysis by using SPSS, Pearson's correlation and chi-square were used to find associations between variables.

Results: The highest percentage (34\%) of the study samples their age group (4-6, 10-12) years respectively and the age at onset asthma (60\%) at (1-3) years. School grade: $(68 \%)$ of study sample was elementary schools. Family history: (48\%) they had history from grand mothers and fathers. Severity of asthma: (46\%) of study sample have moderate attacks, the highest mean score for the Asthma attack triggers was (2.45); Change in daily life was (2.14); Family support was (2.71); Satisfaction with daily life was (2.32) and restriction in participating in physical education class was (2.33). significant correlation and severity of asthma with having cough because of sudden change in temperature, disturbance of sleep, unpleasant feeling to be told about asthma and Emergency visit to hospital.
\end{abstract}

Conclusion: The study concludes asthma has negative Impact on the quality of life style on children at home and school in various ways.

Keywords: Asthma, quality of life, QOLv.3.items.

\section{Introduction}

Asthma is a common chronic illness worldwide which increase reaction of the airways to numerous stimuli including allergens and irritants that cause obstructions of the airways. Contracting of muscles around the airway and infection result in swelling of the coating layers and increased secretion of mucous, so, there were difficulty in breathing and coughing. The most common causes of asthma are infection, exercise, allergens, and irritant air pollution. Children with asthma may have wheezing, coughing, shortness of breath, and chest tightness ${ }^{[1]}$.

Asthma cannot be cured, but could be controlled. Asthmatic children have negatively impact of Health- related quality of life (HRQL) they are required to modify their mode of living to avoid its complications, and have negative impact on their psychological and social well-being.

The strongest risk factors for developing asthma are exposure, especially in infancy, to indoor allergens as domestic mites in bedding, carpets and stuffed furniture, cats and cockroaches; a family history of asthma [2]. Children have smaller airways than adults, which makes asthma especially serious for them. Children with asthma may experience wheezing, coughing, chest tightness, and trouble breathing, especially early in the morning or at night. In the United States, about 9 million children have asthma, which triggers by cold weather, 
pet dander, and being around smoke. Pollutants can also make Children more likely to have respiratory infections as like colds; pollutants can make the lungs even more sensitive to them ${ }^{[3]}$. Also, triggers asthma is allergensmold, pollen, animals, irritants-cigarette smoke, air pollution, weather-cold air, changes in weather, exercise, infections - flu, common cold ${ }^{[2,4]}$.

\section{Method}

Study design, setting, and population: A descriptive study carried out inAl Noor pediatric hospital in Hilla City, during the period 1/5/2020-30/5/2020, the population was (100) children aged 1-12 years; data were collected by questionnaire through direct interview with the mother or caregiver and the child.

Data analysis byusing SPSS (Statistical Package For Social Sciences)

Study Tool: By usingmodified the Quality of Life Questionnaire for Japanese School-aged Children with Asthma Version 3 (JSCA-QOL v.3)items scale.

Data Analysis: Descriptive statistics was done. Pearson'scorrelation and $P$ value of $\leq 0.05$ was considered statistically significant.

\section{Results}

The study assess of asthmas〉 quality Life style among Children aged 1-12 years, the highest percentage (34\%) of study sample at age group (4-6,10-12) years respectively, and the age at onset asthma(60\%) at (1-3) years. (68\%) of study sample was elementary schools; $(58 \%, 44 \%)$ of mothers and fathers had primary school and College and above graduate respectively. (48\%) they had history from grand mothers and fathers. And Severity of asthma (46\%) of study sample was moderate attacks,(Table (1)Table 2: shows the highest mean score for the Asthma attack triggers was (2.45); Change in daily life was (2.14); Family support was (2.71); Satisfaction with daily life was (2.32) and Restriction in participating in physical education class was (2.33).Table 3 : shows significant correlation between age at onset asthma with age and Disturbance of sleep; Mother education with being absent from school; Father education with Having cough because of sudden change in temperature; and Severity of asthma with Having cough because of sudden change in temperature, Disturbance of sleep, Unpleasant feeling to be told about asthma and Emergency visit to hospital.

Table (1): Distribution of study sample according to demographic data and the severity of asthmatic attack. $(\mathbf{n}=\mathbf{1 0 0})$

\begin{tabular}{|c|c|c|c|c|c|c|c|}
\hline Age/year & f. & $\%$ & \multicolumn{3}{|c|}{ Age at onset asthma/year } & f. & $\%$ \\
\hline $1-3$ & 4 & 4 & \multicolumn{3}{|c|}{$1-3$} & 60 & 60 \\
\hline $4-6$ & 34 & 34 & \multicolumn{3}{|c|}{$4-6$} & 34 & 34 \\
\hline $7-9$ & 28 & 28 & \multicolumn{3}{|c|}{$7-9$} & 6 & 6 \\
\hline $10-12$ & 34 & 34 & \multicolumn{3}{|c|}{ Total } & 100 & 100 \\
\hline Total & 100 & 100 & & & & & \\
\hline School grade & f. & $\%$ & \multicolumn{3}{|c|}{ Family history } & f. & $\%$ \\
\hline Kindergarten & 32 & 32 & \multicolumn{3}{|c|}{ father } & 34 & 34 \\
\hline Elementary & 68 & 68 & \multicolumn{3}{|c|}{ mother } & 18 & 18 \\
\hline & & & \multicolumn{3}{|c|}{ others } & 48 & 48 \\
\hline Educational level for & \multicolumn{2}{|c|}{ Mother } & \multicolumn{4}{|c|}{ Father } & \\
\hline & f. & $\%$ & \multicolumn{3}{|c|}{ f. } & $\%$ & \\
\hline Primary & 58 & 58 & \multicolumn{3}{|c|}{44} & 44 & \\
\hline Secondary & 14 & 14 & \multicolumn{3}{|c|}{16} & 16 & \\
\hline College \& above & 28 & 28 & \multicolumn{3}{|c|}{40} & 40 & \\
\hline \multirow[t]{2}{*}{ Severity of asthma } & Mild & $\%$ & Moderate & $\%$ & Sever & \multicolumn{2}{|c|}{$\%$} \\
\hline & 10 & 10 & 46 & 46 & 44 & \multicolumn{2}{|c|}{44} \\
\hline
\end{tabular}


Table (1) shows that the Age group (years): highest percentage (34\%) of study sample their age group (46,10-12) years respectively, and the mean with SD. was $12.5 \pm 7.14$ and the age at onset asthma(60\%) at (1-3) years.

School grade: (68\%) of study sample was elementary schools; $(58 \%, 44 \%)$ of mothers and fathers

had primary school and College and above graduate respectively.

Family history: (48\%) they had history from grand mothers and fathers.

Severity of asthma: (46\%) of study sample was moderate attacks,

Table (2) : Distribution of study sample according to JSCA-QOL v.3. (N=100)

\begin{tabular}{|c|c|c|c|c|c|c|c|c|}
\hline & JSCA-QOL v.3 items & Never & $\%$ & Some time & $\%$ & Always & $\%$ & Mean \\
\hline \multicolumn{9}{|c|}{ Asthma attack triggers. } \\
\hline 1 & Having cough because of cigarette smoke. & 2 & 4 & 11 & 22 & 37 & 74 & 2.7 \\
\hline 2 & Having cough in crowd. & 2 & 4 & 25 & 50 & 23 & 46 & 2.42 \\
\hline \multirow[t]{2}{*}{3} & Having cough because of sudden change in temperature. & 9 & 18 & 21 & 42 & 20 & 40 & 2.22 \\
\hline & Total mean of score & & & & & & & 2.45 \\
\hline \multicolumn{9}{|c|}{ Change in daily life } \\
\hline 1 & Being absent from school. & 13 & 26 & 26 & 52 & 11 & 22 & 1.96 \\
\hline 2 & Unpleasant feeling to be told about asthma. & 7 & 14 & 19 & 38 & 24 & 48 & 2.34 \\
\hline 3 & Disturbance of sleep. & 21 & 42 & 0 & 0 & 29 & 58 & 2.58 \\
\hline 4 & Emergency visit to hospital. & 3 & 6 & 16 & 32 & 31 & 62 & 2.56 \\
\hline 5 & Leaving school earlier. & 30 & 60 & 14 & 28 & 6 & 12 & 1.52 \\
\hline \multirow[t]{2}{*}{6} & Giving family trouble. & 16 & 32 & 25 & 50 & 9 & 18 & 1.86 \\
\hline & Total mean of score & & & & & & & 2.14 \\
\hline \multicolumn{9}{|c|}{ Family support } \\
\hline 1 & Family support when having an asthma attack. & 3 & 6 & 1 & 2 & 46 & 92 & 2.86 \\
\hline 2 & Family's careful consideration to prevent asthma attacks. & 11 & 22 & 0 & 0 & 39 & 78 & 2.78 \\
\hline 3 & $\begin{array}{l}\text { Being praised for making efforts toward asthma } \\
\text { treatment. }\end{array}$ & 3 & 6 & 18 & 36 & 29 & 58 & 2.52 \\
\hline \multirow[t]{2}{*}{4} & Family support in daily life. & 1 & 2 & 13 & 26 & 36 & 72 & 2.7 \\
\hline & Total mean of score & & & & & & & 2.71 \\
\hline \multicolumn{9}{|c|}{ Satisfaction with daily life } \\
\hline 1 & Being as healthy as friends. & 10 & 20 & 22 & 44 & 18 & 36 & 2.16 \\
\hline 2 & Enjoying daily life. & 6 & 12 & 20 & 40 & 24 & 48 & 2.36 \\
\hline 3 & Enjoying at play. & 9 & 18 & 17 & 34 & 24 & 48 & 2.3 \\
\hline 4 & Enjoying school life. & 8 & 16 & 18 & 36 & 24 & 48 & 2.32 \\
\hline 5 & Enjoying what I want to do. & 10 & 20 & 15 & 30 & 25 & 50 & 2.3 \\
\hline 6 & Spending daily life with satisfaction. & 6 & 12 & 27 & 54 & 17 & 34 & 2.22 \\
\hline 7 & Having dreams or hopes for the future. & 4 & 8 & 17 & 34 & 29 & 58 & 2.5 \\
\hline \multirow[t]{2}{*}{8} & Spending daily life as well as friends does. & 4 & 8 & 21 & 42 & 25 & 50 & 2.42 \\
\hline & Total mean of score & & & & & & & 2.32 \\
\hline
\end{tabular}




\begin{tabular}{|c|c|c|c|c|c|c|c|c|}
\hline & JSCA-QOL v.3 items & Never & $\%$ & Some time & $\%$ & Always & $\%$ & Mean \\
\hline \multicolumn{9}{|c|}{ Restriction in participating in physical education class. } \\
\hline 1 & Restriction in participating in sports. & 9 & 18 & 20 & 40 & 21 & 42 & 2.42 \\
\hline 2 & Difficulty in playing cheerfully with friends. & 9 & 18 & 18 & 36 & 23 & 46 & 2.28 \\
\hline \multirow[t]{3}{*}{3} & Restriction in participating in physical education class. & 9 & 18 & 17 & 34 & 24 & 48 & 2.3 \\
\hline & Total mean of score & & & & & & & 2.33 \\
\hline & Cut-off point $=2$ & & & & & & & \\
\hline
\end{tabular}

Table 2: shows the highest mean score for the Asthma attack triggers was (2.45); Change in daily life was (2.14); Family support was (2.71); Satisfaction with daily life was (2.32) and Restriction in participating in physical education class was (2.33).

Table3: the correlation between some demographic data and JSCA-QOLv.3.items. (N=100)

\begin{tabular}{|c|c|c|}
\hline Correlation & Pearson correlation & Sig.(2-taild) \\
\hline Age*age at onset asthma & $.290^{*}$ & .041 \\
\hline Mother education*being absent from school & $-.382 * *$ & .006 \\
\hline Father education* Having cough because of sudden change in temperature. & $-.286^{*}$ & .044 \\
\hline Severity of asthma* Father education & $-.413 * *$ & .003 \\
\hline Severity of asthma* Having cough because of sudden change in temperature. & $.306^{*}$ & .031 \\
\hline Severity of asthma* Disturbance of sleep & $.382 * *$ & .006 \\
\hline Severity of asthma* Unpleasant feeling to be told about asthma. & $.485^{* *}$ & .000 \\
\hline Severity of asthma* Emergency visit to hospital. & 0329* & .020 \\
\hline Age at onset asthma* Disturbance of sleep & $-.479 * *$ & .000 \\
\hline
\end{tabular}

*significant at $\leq 0.05, * *$ significant at $\leq 0.01$

Table 3: shows significant correlation between age at onset asthma with age and Disturbance of sleep; Mother education with being absent from school; Father education with Having cough because of sudden change in temperature; and Severity of asthma with Having cough because of sudden change in temperature, Disturbance of sleep, Unpleasant feeling to be told about asthma and Emergency visit to hospital.

\section{Discussion}

Demographics of the Sample: The Age group (years): highest percentage (34\%) of study sample their age group (4-6, 10-12) years respectively.

That agree with Iraqi Family Health Survey stated that the prevalence rates increase progressively with age and the age at onset asthma (60\%) at (1-3) years. School grade: $(68 \%)$ of study sample was elementary schools; $(58 \%, 44 \%)$ of mothers and fathers had primary school and College and above graduate respectively.
Family history: (48\%) they had history from grand mothers and fathers and the Severity of asthma: $(46 \%)$ of study sample was moderate attacks ${ }^{[5]}$. Also a study mentioned that parents' educational level and family income were positively related to asthma control status $^{[6]}$.

A study found that parents with low educational levels are associated with medication underuse. Also, studies in the United Kingdom and Germany have revealed that severe asthma is correlated with decreasing socioeconomic status. Also, $61.7 \%$ of the patients had history of smoking exposure in their home having poor control asthma ${ }^{[1]}$. Go to:

Although little is known about the scope to which the age at asthma first began is associated with the presence, frequency, or severity of subsequent respiratory health outcomes ${ }^{[7]}$. 
Quality of Life as Assessed by JSCA-QOL v.3:

The result of this study revealed that there were high negative impact among quality of life for asthmatic children that agree with study conducted by The American Lung Association, states about the secondhand smoke which estimated 400,000 to 1 million children with asthma and their condition worsened andThe Centers for Disease Control and Prevention (CDC) state that children with asthma are more likely to have repetitive visit to hospital, emergency, and urgent care visits than adults with asthma ${ }^{[8]}$.

The study shows significant correlation between age at onset asthma with age and Disturbance of sleep; Mother education with being absent from school; Father education with Having cough because of sudden change in temperature; and Severity of asthma with Having cough because of sudden change in temperature, Disturbance of sleep, Unpleasant feeling to be told about asthma and Emergency visit to hospital.

That result agree with study stated that Asthma influenced the life of the children physically, emotionally and socially and consequences of asthma on peer relationships, the dependence on medication, shortness of breath, cough, limitations in activities and limitations due to the response on cigarette smoke exposure[9].

Also, study mentioned that there were association between severity of asthma and child's quality of life and between routine burden and quality of life in children with asthma ${ }^{[10]}$.

Astudy showed that while parents of children with intermittent asthma and parents of younger children presented higher levels of caregiving burden,

Significant negative and positive associations were found between burden measurements and quality of life ${ }^{[11]}$.

Also,studyStated that Significantly poorer quality of life was observed in children with uncontrolled asthma $(\mathrm{p}=<0.001)$. Children with controlled and uncontrolled asthma were equally affected psychosocially with no relation between asthma control and their psychosocial well-being $(\mathrm{p}=0.58)^{[12]}$.

Children are underestimating the level of disease severity. The accurateness of symptom perception depends on cognitive and emotional state, previous life experiences, attributions, related information, attention and learning processes, and prior asthma attacks, the sensation of unpleasantness related to dyspnea, rather than its sensory strength, all that linked to affecting stimuli ${ }^{[13]}$. The cohorts study revealed that the average increasing incidence of $19.1 \%$. but it keep on steady among children aged 3 years or older, and increased very quickly only among children over 3 years, from $1.3 \%$ (95\% CI, 1.2-1.3) to $13.7 \%$ (95\% CI, 13.5- 13.9) $(\mathrm{P}<.0001)^{[14]}$.

\section{Conclusion}

The findings shows significant correlation between age at onset asthma with age and Disturbance of sleep; Mother education with being absent from school; Father education with Having cough because of sudden change in temperature; and Severity of asthma with Having cough because of sudden change in temperature, Disturbance of sleep, Unpleasant feeling to be told about asthma and Emergency visit to hospital.

Recommendations: This study recommends further researches are needed to study the psychological effect of asthma, study the risk factors leading to poor asthma control.

Availability of data and materials

Available on reasonable request.

Author's Contributions: All the authors are equally contributed to complete this research.

Acknowledgements: We wish to express our sincere appreciation to all study participant>s for their help and patience. We also thank and appreciate the nurses staff of Al Noor Pediatric Hospital in HillaCity, for assistant during data collection.

Funding: The authors did not receive any external funding for this work.

Conflicts of Interest: The authors declare no conflicts of interest regarding the publication of this paper.

Acknowledgment: The authors would like to thank all mothers and child who involve in this study.

Ethical Consideration: The researchers obtained an approval from Al Noor Pediatric Hospital in Hilla City. And the varbal approval of the mother $>$ s participants in the research project. 
Consent for Publication: Not applicable.

Competing Interests: The authors declare that they have no competing interests.

\section{References}

[1. Foundation of America:Asthma and Allergy, New England Chapter2020. Website: www. asthmaandallergies.org e-mail: david@aafane.org

2. WHO: Bronchial asthma Fact sheet,20 May 2020.

3. Joseph, E.P.B :Air Pollution and Asthma: Date reviewed: September 2017

4. American Academy of Pediatrics: Nutrition: What Every Parent Needs to Know: Asthma and Food Allergies: Last Updated 11/21/2015

5. Iraq Family Health Survey IFHS, 2006/7

6. Banjari M., Kano Y., Almadani S, A. Basakran A., Al-Hindi M., and Alahmadi T.: The Relation between Asthma Control and Quality of Life in Children: «International Journal of Pediatrics». Volume 2018, Article ID 6517329, 6 pages https:// doi.org/10.1155/2018/6517329.

7. Maria C. Mirabelli, Suzanne F. Beavers, Arjun B. Chatterjee, and Jeanne E. Moorman: Age at asthma onset and subsequent asthma outcomes among adults with active asthma"Respir Med". $2013 \mathrm{Dec}$; 107(12): 1829-1836. Published online 2013 Oct 5. doi: 10.1016/j.rmed.2013.09.022

8. Holland K.: The Differences Between Childhood and Adult-Onset Asthma; Medically reviewed by Karen Gill, MD on October 6, 2017. https:// www.healthline.com/health/asthma/differenceschildhood-adult-onset-asthma

9. Lisette van den B, Sabine, K, Vinca L, Peter L, Jean M, Gordon S, and Tjard S: How does asthma influence the daily life of children? Results of focus group interviews;»Health Qual Life Outcomes». 2010; 8: 5. Published online 2010 Jan 14. doi: 10.1186/1477-7525-8-5

10. Samantha A. Miadich, Robin S. Everhart, Adrienne P. Borschuk, Marcia A. Winter, and Barbara H. Fiese: Quality of Life in Children With Asthma: A Developmental Perspective"JPediatr Psychol". 2015 Aug; 40(7): 672-679.

11. Silva, N., Carona, C., Crespo, C., \& Canavarro, M. C. (2015). Caregiving burden and uplifts: A contradiction or a protective partnership for the quality of life of parents and their children with asthma? «Journal of Family Psychology», 29(2), 151-161. http://dx.doi.org/10.1037/fam0000071

12. Banjari M., KanoY., AlmadaniS., Basakran A., AlHindi M., and Alahmadi T.: The Relation between Asthma Control and Quality of Life in Children: «International Journal of Pediatrics» .Volume 2018, Article ID 6517329, 6 pages https://doi. org/10.1155/2018/6517329 Received 26 January 2018; Revised 20 May 2018; Accepted 30 May 2018; Published 3 July 2018

13. BaiardiniI., Sicuro F., BalbiF.,Canonica G.W. and Braido F.: Psychological aspects in asthma: do psychological factors affect asthma management? “Asthma Research and Practice"20151:7https:// doi.org/10.1186/s40733-015-0007-1

14. Radhakrishnan DK, Sharon D. D., Guttmann A., Salimah Z. S., Liu K., and Teresa To, London and Toronto, Ontario, Canada «J Allergy Clin Immunol» 2014;134:1057-62.

15. Midori A., Taichi S., Kiyomi M., Shinpei T. and Ayako I.:Reliability and Validity of the Self-report Quality of Life Questionnaire for Japanese Schoolaged Children with Asthma (JSCA-QOL v.3). 